\title{
Research on Risk Governance Order of Spring Festival Tourism Emergency-Based on Mass Passenger Stranding Incident in Haikou Port
}

\author{
Weicheng Lian \\ School of Public Management, Jinan University, Guangzhou, China \\ Email:wilson@stu2017.jnu.edu.cn
}

How to cite this paper: Lian, W. C. (2020). Research on Risk Governance Order of Spring Festival Tourism Emergency-Based on Mass Passenger Stranding Incident in Haikou Port. Open Journal of Social Sciences, 8, 119-127.

https://doi.org/10.4236/jss.2020.82011

Received: January 17, 2020

Accepted: February 23, 2020

Published: February 26, 2020

Copyright $\odot 2020$ by author(s) and Scientific Research Publishing Inc. This work is licensed under the Creative Commons Attribution International License (CC BY 4.0).

http://creativecommons.org/licenses/by/4.0/

(c) (i) Open Access

\begin{abstract}
Spring Festival holiday tourism often brings a large-scale population flow, which aggravates the pressure of transportation. There are risks in the three levels of "physiology-psychology-society" that need to be prevented and controlled. It has become a public security field that the state and society focus on. This paper analyzes the role and role of different subjects in risk management from the perspective of order, taking the large-scale passenger detention and serious traffic congestion in Haikou Port caused by heavy fog in Hainan Province as an example. In the emergency management of "outlying islands" emergencies, the government conducts emergency mobilization through authoritative order, and optimizes resource integration order, information communication order, and inter-government collaborative cooperation order. Social forces actively participate in risk management. The market order gives priority to emergency management. The media and online platforms optimize information service order, control social order, and innovate service efficiency. Thus, Hainan province's emergency management ability in response to the peak of Spring Festival is improved, the emergency management order is optimized, the cooperation order is expanded, the construction and innovation of urban and grass-roots emergency management system are promoted, and the tourism order is guaranteed.
\end{abstract}

\section{Keywords}

Tourism Emergency, Spring Festival, Passenger Detention, Order, Risk Management

\section{Question}

In recent years, the Spring Festival holiday tourism market is hot. According to 
Hainan Daily, Hainan Province, as an important tourist source, received 5.6755 million tourists during the Spring Festival Golden Week in 2018, up 10.0\% year on year. Due to the particularity of Hainan's geographical location, most of the passengers and all the vehicles are transported by the passenger roll boat in Qiongzhou Strait, whose operation order is related to the people's travel safety and the development of Hainan's economy and society. For this reason, Hainan province makes a key deployment of "Spring Festival transport" in advance every year, and starts corresponding emergency work plan according to the estimated passenger flow every year, which has mature work experience in transportation and passenger flow dredging during the Spring Festival. According to the normal operation order, Hainan Province has the ability to ensure the smooth operation of Qiongzhou Strait. But the reality is that Haikou's three major ports have been suspended for many times due to heavy fog weather, resulting in large-scale passenger detention and serious traffic congestion. Since the third day of 2018, tens of thousands of vehicles have been stranded every day, with a peak period of more than 20,000 vehicles, a queue of 20 kilometers long and nearly 100,000 passengers stranded.

There is complexity in a risk society, and the input of special factors causes the original order to appear out of order in unconventional emergencies (Becken \& Hughey, 2013). By clarifying the elements of a complex disaster system, the pregnancy environment of the outlying island incident is predictable. One is that traffic peaks will occur during the Spring Festival return journey. The second is that the number of self-driving cars entering the island during the Spring Festival has increased by $15 \%$ each year. It is estimated that 830,000 vehicles will enter and leave Hainan during the Spring Festival this year. Liu Dong, director of the Haikou Port and Shipping Bureau, said that under good navigation conditions, Haikou's shipping capacity was sufficient to handle the peak return. However, the fog that has not been encountered in 67 years has become a potential hazard. The foggy weather can be predicted in advance at the technical level. The local government has not included the risks brought by the meteorological elements into the emergency preparedness system during the Spring Festival, leading to inadequate emergency response. Under the stacked risk structure, the ship outages problem caused by heavy fog is harder to predict and control than other factors, and it also challenges Hainan's emergency management during the Spring Festival.

The public crisis triggered by public emergencies has an impact on the orderly results, states, and situations of the original people in groups, organizations, communities, and social activities (Chaowu \& Shifei, 2013). The actual state of social crisis has created a strong and universal need for the restoration and reconstruction of social order (Kendrick, 2006). Therefore, within eight days of initiating the first-level emergency response for passenger and freight ro-ro transportation emergencies, Haikou City mobilized and united as one, to do a good job of traffic guidance and service guarantee 24 hours a day, making proper ar- 
wo rangements for the lives of tens of thousands of stranded tourists. In responding to this unconventional incident, what are the risks of order control? How does the order of emergency management work? What is the order of local government, market, social and online media to participate in risk governance? How to protect the rights and order of stranded passengers? What governance strategies are there for order optimization? This study introduces the perspective of order into the emergency management of outlying island incident, discusses the order operation status in practice, and provides experience for future tourism risk management.

\section{Order Status and Analytical Path}

Outlying island incident is an unconventional emergency. Multiple suspensions have brought about obvious traffic congestion and large-scale passenger detention. Human beings are both disaster-receiving bodies and disaster-causing factors. The occurrence of disasters is the result of the inability of disaster-receiving bodies to adapt to environmental changes (Foster \& K, 2000), causing human beings to urgently prevent and control risks at the three levels of "physical, psychological, and social". At the physiological level, how do the living conditions of stranded passengers remain normal? How to ensure the food and drink, rest and stable physical condition of stranded passengers? At the psychological level, passengers experience psychological and emotional anxiety due to long stays, and a few stranded vehicles honked in protest. How to resolve the mentality crisis of passengers? At the social level, online media and the public have discussed the outlying island incident, and even derived the online public opinion of "expensive air tickets for outlying island". How can we construct and regulate the order of public opinion? The rights of stranded passengers need to be safeguarded, and the image of local governments and Hainan cities also needs to be maintained. So far, this article has constructed the evolution logic of risk and order crisis. However, in a risky environment, how to avoid the derivative risks caused by disorder?

Faced with a crisis of order, different subjects participate in risk governance, but due to differences in governance resources and capabilities, different subjects assume different roles in the provision of emergency public services. Cooperative governance under a certain order is formed between various governing bodies. The order reflects the "process-behavior-structure" of different subjects. What is the order status of government, market, society, and network media in emergency management? What is the government's action strategy in emergency management? How to prepare and organize resources, how to ensure authority and order, and how to achieve inter-governmental cooperation order? Under the governance structure of "strong government-strong society", how can social forces participate in risk governance? In the information age of the Internet, how does the network media optimize the order of information services, how to control the order of public opinion, and how to innovate the order of service effi- 
ciency?

\section{Subject Order and Practical Practice}

\subsection{Strong Government Participation in Risk Governance Order}

In risk governance, the government assumes the main responsibility of "disaster prevention, mitigation, and relief" public services. The government has a basic position in resource allocation and continuous strengthening of social control and mobilization capabilities, presenting China's emergency management Features of "Fist Mode". The emergency management of the outlying island incident has become an inter-government governance goal. Local governments use resources to integrate resources and mobilize the province and the city's forces to participate in risk governance from the top down, and actively build the government's authority and service order in emergency management.

\subsubsection{The Original Order of Emergency Preparedness}

The three major ports in Haikou are responsible for the "large flow" of transportation during the Spring Festival each year. Although emergency incidents have occurred, the Haikou City Government has made relatively sufficient preparations in the preliminary emergency work, but the "fog" has turned into the core hazard factor. However, the previous work has also enabled the government to respond in a timely manner to the crisis of order, which is also the key guarantee for the efficiency of risk governance. Prior to the outlying island incident, Hainan Province and Haikou City deployed ahead of time for the "Spring Festival Transport" to provide timely and effective responses to the transportation pressure in specific time periods.

In terms of the plan system, Haikou City has formulated the emergency plan for the Spring Festival Golden Week. In response to the safety of port transportation, Haikou City has launched the "Emergency Plan for Passenger and Freight Ro-Ro Transport Emergency Contingencies”, and Haikou Maritime Bureau also formulated the "2018 Spring Transport Water Traffic Safety Supervision Work Plan.” In terms of information communication, the Haikou Government requires the improvement of the communication and release of the Spring Festival information, actively connects with various media and Internet platforms, and timely releases relevant information on transportation, ticketing, and weather, and especially plays the role of the 12345 hotline and Coconut City Citizen Cloud. In terms of collaboration, Haikou City requires the Communications, Port and Navigation Bureau to take the initiative to communicate, coordinate and dock with Qiongzhou Straits Office, Zhanjiang, Guangdong and other relevant management departments, prepare in advance to ensure the smooth flow of information, and coordinate the transportation capacity of Xiuying Port and Xinhai Port. To this end, the Haikou Maritime Safety Administration and the Zhanjiang Maritime Safety Administration held the Qiongzhou Strait Passenger Transport Spring Festival Transport Deployment Meeting to carefully organize 
the safety protection work for the Qiongzhou Strait Spring Transport in 2018. In response to the severe weather such as strong winds and dense fog during the Spring Festival, which affects the navigation safety of the ship, Haikou Maritime Bureau communicated with the meteorological department to timely release sailing information to minimize the impact of severe weather on the safety of water transportation during the Spring Festival.

\subsubsection{Authoritative Order for Emergency Mobilization}

"Control, absorption and collaboration" is the path choice of social order in the context of risk and transformation (Covello \& Mumpower, 1985). The government controls the flow order of resources and the communication order of information under risk scenarios, mobilizes and absorbs social forces to participate in risk governance, and attaches importance to improving the order of inter-governmental and cross-regional cooperation. The choice of these paths is inseparable from China's "emergency management system." For the government, the organizational climate and management process control have an impact on the organization's operational order. Especially in the emergency management work, it is necessary to create an overall atmosphere of "disaster prevention, mitigation, and relief", and to mobilize and control the order of risk governance through the control of the political system. Facing the sudden incident of large-scale vehicles and passengers stranded due to the suspension, the leaders of Hainan Province and Haikou City rushed to the "front line" of emergency management. This is not only the constraint of the political system, but also the leadership art of "mobilization", which reflects the "determination" of Hainan Province and Haikou municipal governments in risk management. Under China's emergency management system, the vertical bureaucratic system exerts authority and order, and mobilizes all government forces and social resources to deal with it. Haikou City launched a first-level emergency response to passenger and freight ro-ro transportation emergencies, requiring that apart from the departments and units involved in emergency guards and front-line service guarantees, other departments and units in Haikou City temporarily suspended to make way for tourist vehicles.

\subsubsection{Service Order for Emergency Response}

The three major port areas of Haikou have achieved full coverage of voluntary services, full coverage of sanitary cleaning, full coverage of medical assistance, full coverage of emergency protection, and full coverage of order maintenance. Many functional departments and cadres and workers in the city gave up the Spring Festival holiday, fully serviced and guaranteed the work of "anti-fog and guaranteed transportation", and worked overnight to work hard. As the outlying island incident involved a large number of stranded passengers and vehicles, multiple functional departments were required for emergency coordination. In fact, how to coordinate the work between functional departments required a unified emergency command. To this end, Haikou City quickly established a 
port area headquarters, consisting of 13 units, including the Provincial Straits Office, the Municipal Communications and Harbor Bureau, the Municipal Party Committee Propaganda Department, and the Municipal Traffic Police Detachment.

In terms of information release order, Haikou established a half-hour information reporting and release mechanism, arranged a spokesperson for Haikou Port to predict the navigation situation, released real-time traffic conditions at Haikou Port. Through timely, fast and smooth information release and publicity propaganda, the government guided tourists to travel on peaks. During the emergency response period, Haikou City held a press briefing to respond to the peak of the return trip to report the situation of passengers and vehicles stranded across the sea during the Spring Festival and countermeasures. In terms of resource integration order, Haikou City has set up temporary emergency resettlement points and evacuation points in the three major ports to facilitate stranded passengers to rest and stay overnight, and set up fixed comprehensive service points. At the same time, Haikou sorted out the interiors of the three port areas one by one, maximizing the parking space, and building temporary emergency parking lots to avoid traffic jams on the roads.

\subsubsection{Inter-Governmental Cooperative Order}

The various departments of Haikou City Government have their own responsibilities in risk management, but in reality, it is necessary to build a cooperative and coordinated order to promote the integration of resources through collaboration and cooperation to achieve a seamless gap in public services. In terms of traffic dredging, the Xiuying District Government of Haikou City, Haikou Urban Construction Group and the traffic police detachment worked together to promote the construction of the first-phase parking lot in Xinhai Port. In terms of material supply, the Civil Affairs Bureau and the Commerce Bureau ensure the supply of materials. In terms of volunteer services, the Communist Youth League Committee and the Municipal Civilization Office actively integrated the resources of all parties, united the four district and municipal related functional departments, and mobilized organizations and caring companies to send volunteers to do a good job in guaranteeing volunteer service during the Spring Festival return journey. In terms of meteorological release, the Municipal Meteorological Bureau, Communications Bureau, Haikou Maritime Bureau and Zhanjiang Maritime Bureau jointly issued weather conditions for navigation in Qiongzhou Strait. In terms of information technology, emergency support services require the technical support of the information platform, and Haikou City Science, Technology and Industry Bureau is responsible for the city's national economic and social service informatization.

\subsection{Strong Social Participation in Risk Governance Order}

The government is constrained by its capabilities and resources in emergency 
management. Especially when facing large-scale stranded passengers, it is difficult to rely on the government to achieve seamless public services. The government assumes more of the role of command and coordination in emergency management, and the participation of social forces is needed to truly provide services. Therefore, the transition from authoritative order to autonomous order is the direction of grassroots social governance transformation (Klinke \& Renn, 2002), and it is also the direction of social risk governance transformation. The "fist model" of China's emergency management work reflects not only the core organization and mobilization capabilities of the government, but also the basic forces of society. In the future, emergency management in China will be characterized by a "strong government-a strong society", and social participation can achieve a wide range of emergency public services. After the outlying island incident, the most frequent contact among stranded passengers was "volunteers", which showed the social forces in the era of "community of fate". In addition to voluntary services provided by government organizations, many are spontaneously involved.

\subsection{Market Participation Risk Governance Order}

The market emphasizes "economy and efficiency", but in the face of social risk scenarios, how can the market serve the optimization of public order? In the emergency response work, the government will integrate market resources and give play to the advantages of market efficiency, but it cannot destroy the legitimate operating logic of the market, which is reflected in "guarantee social benefits on the basis of economy and pursue response efficiency on the basis of emergency work."

During the emergency response to the outlying island incident, three typical companies participated-airlines, port shipping companies, and bus groups. After the "high-price ticket" incident, airlines immediately rectified online ticket prices to avoid misunderstandings among consumers. At the same time, in order to alleviate the pressure of passengers leaving the island, airlines actively deploy wide-body aircraft, increase wide-body aircraft overnight and other methods, increase capacity deployment, increase the number of available seats, assist more passengers to return, and do their best to provide shipping services to protect passengers successfully reached their destination.

The port and shipping enterprises adopt an active loading and unloading operation mode. By adopting measures such as diverting passengers and vehicles in advance to get on and off the ship, and preloading on shore, they maintain precise management and efficient operation, increase the efficiency of loading and unloading, and minimize the number of detained passengers and incremental pressure. Facing the pressure of inbound passenger flow and stranded passengers, Haikou Bus Group assisted the transportation department, traffic police department and the three ports to jointly formulate emergency strategies and dispatch other routes of buses to evacuate passengers to the port. 


\subsection{Network and Media Platform Participation in Risk Governance Order}

The information element is an important response resource in the emergency management process, especially the incident involved a large number of stranded passengers. How to pass service information to stranded passengers tests the local government's governance ability. When the information is asymmetric or the transmission fails, it will lead to a potential crisis of trust. How to ensure the government's credibility in emergency management through the Internet and media platforms? The media and network platforms play the role of information media in emergency management. More and more people are paying attention to the media through convenient network platforms to obtain information that is valuable to them. This has also caused the society to raise the demand for public information. How to protect public order? The government proactively adapts to the "Internet +" era, and releases information through the Internet and news media to improve the efficiency of the responsive government.

\section{Summary and Reflection}

From Hainan Provincial Party Committee and Provincial Government to functional units in Haikou City, as well as all sectors of society, they have focused their attention on anti-fog and anti-blocking actions, showing the order of "strong government-strong society". The government undertakes the authority and order in emergency management, and plays a leading role by integrating resources and promoting collaborative cooperation. Social force participation has become a necessity for cooperative governance of "risk society". Market order is given priority to emergency management. Media and online platforms serve as information communication channels to stabilize social order. In the order of multi-agent participation in risk governance, fully mobilize social resources to jointly respond to emergencies, maintain social order, and achieve order return after emergencies.

The outlying island incident has enhanced Hainan Province and Haikou City's emergency management capabilities in response to the peak of the Spring Festival Transport, and further optimized the related emergency management order in the future. However, in actual operation, there is still much room for improvement in the order of monitoring and early warning, information release, and coordination and cooperation. In the face of emergencies, there is more a temporary order of action. In the future, experience and normal work items need to be formed to construct Public interest-based risk prevention and control order to improve urban resilience to risks. From the perspective of concepts, systems, and actions, we will rebuild trust, expand cooperation order, advance the construction and innovation of urban and grass-roots emergency management systems, and ensure tourism order. In terms of technical governance, we will strengthen the construction of waiting areas in the port area and the design 
of sparse traffic lines to enhance port shipping capabilities. At the same time, we will strengthen the construction of smart ports and improve the information-based ticket control system.

\section{Conflicts of Interest}

The author declares no conflicts of interest regarding the publication of this paper.

\section{References}

Becken, S., \& Hughey, K. F. D. (2013). Linking Tourism into Emergency Management Structures to Enhance Disaster Risk Reduction. Tourism Management, 36, 77-85. https://doi.org/10.1016/j.tourman.2012.11.006

Chaowu, X., \& Shifei, S. (2013). Influences of Environmental Risks of Tourist Destinations on Tourism Emergency Events in China and Their Regional Distributions. Progress in Geography, 32, 455-464.

Covello, V. T., \& Mumpower, J. (1985). Risk Analysis and Risk Management: An Historical Perspective. Risk Analysis, 5, 103-120. https://doi.org/10.1111/j.1539-6924.1985.tb00159.x

Foster, \& K, R. (2000). Risk Management: Science and the Precautionary Principle. Science, 288, 979-981. https://doi.org/10.1126/science.288.5468.979

Kendrick, T. (2006). The Risk Management Universe: A Guided Tour. [Rinshō ketsueki] The Japanese Journal of Clinical Hematology, 24, 1373-1377.

Klinke, A., \& Renn, O. (2002). A New Approach to Risk Evaluation and Management: Risk-Based, Precaution-Based, and Discourse-Based Strategies. Risk Analysis: An Official Publication of the Society for Risk Analysis, 22, 1071-1094.

https://doi.org/10.1111/1539-6924.00274 